\title{
THE PRESSOR EFFECT OF THE ANTIDIURETIC PRINCIPLE OF THE POSTERIOR PITUITARY IN ORTHOSTATIC HYPOTENSION ${ }^{1}$
}

\author{
By HENRY N. WAGNER, JR. AND EUGENE BRAUNWALD
}

(From the National Heart Institute, National Institutes of Health, Bethesda, Maryland)

(Submitted for publication July 18, 1956; accepted August 31, 1956)

Although the antidiuretic property of posterior pituitary extracts is well established, investigators have repeatedly failed to demonstrate a pressor effect of these substances in man $(1,2)$. Consequently, the hemodynamic effects of posterior pituitary hormones have received relatively little attention. However, it is known that posterior pituitary extracts do produce an increase in arterial pressure after injection into anesthetized or spinal animals $(3,4)$. The purpose of this report is to present observations on a disease state in man in which it was found that posterior pituitary hormones have a marked effect on arterial pressure.

\section{DESCRIPTION OF PATIENTS}

The three patients under investigation had postural hypotension, hypohidrosis, and impotence, a clinical syndrome first described by Bradbury and Eggleston (5).

Patient H. C. (NIH No. 01-16-06) was a 55-year-old former maintenance man. Ten years prior to his admission he began to tire easily. Several months after the onset of these symptoms, the patient had a right inguinal herniorraphy under spinal anesthesia. Following operation, he noted the sudden onset of symptoms related to orthostatic hypotension, impotence and cessation of sweating in the lower half of his body. Since then his disease has been progressive both symptomatically and by objective measurements.

Patient B. B. (NIH No. 01-19-93) was a 66-year-old, retired sea captain. Approximately 15 years ago, a gradual diminution of sweating occurred. Ten years prior to admission, he noted the onset of symptoms of orthostatic hypotension during exposure to high environmental temperatures. His symptoms of heat intolerance, weakness and syncope progressed until one year ago he was forced to retire.

Patient W. A. (NIH No. 00-08-52) was a 66-yearold economist. Eighteen years ago the patient had the sudden onset of severe postural hypotension and impotence. He stated that he has sweated less than other persons throughout his life. Subjectively, he believes that his symptoms have progressed. He had, however, been able to maintain an office job throughout his illness.

1 Presented before the 48th Annual Meeting of the Society for Clinical Investigation, Atlantic City, N. J., April 30, 1956.
Patients H. C. and W. A. were usually normotensive in the recumbent position. Patient B. B. was usually hypotensive when recumbent, with pressures in the range of $80 / 60 \mathrm{~mm}$. Hg. Arterial pressures, however, varied greatly with activity and bodily position. In none of the patients was there evidence of diabetes mellitus, amyloidosis, general debility, syphilis, Addison's disease or any somatic neurological disorder.

In all three patients graded passive tilting in the head-up position from 5 to 40 degrees resulted in a progressively lowered arterial pressure, with mild or no associated symptoms. In all patients, passive tilting greater than 45 degrees resulted in weakness, drowsiness, blurring of vision, inability to speak and syncope within several minutes. Arterial pressures fell to levels unobtainable by sphygmomanometry.

Following the fall in arterial pressure associated with passive tilting, a characteristic "overshoot" of the pressure to levels higher than the baseline pressure occurred after the patients resumed the recumbent position. Following the Valsalva maneuver, in none of the patients was there the normal "overshoot" of the arterial pressure to levels higher than the baseline (6).

In patient W. A., an increase of pulse rate of 15 to 20 beats per minute occurred on standing, passive tilting, and during the Valsalva maneuver. In patients $H$. $C$. and B. B., no increase in pulse rate occurred with the fall in arterial pressure associated with standing, passive tilting or the Valsalva maneuver. However, during hospitalization nine years ago patient $\mathrm{H}$. C., on standing, developed a tachycardia together with a marked fall in arterial pressure.

In all three patients there was supersensitivity to the pressor effect of norepinephrine. A rise in systolic arterial pressure to levels of 180 to $220 \mathrm{~mm}$. $\mathrm{Hg}$ occurred with intravenous infusions of less than one microgram per minute of Levophed@. In all patients, atropine in doses up to $4 \mathrm{mgm}$. subcutaneously failed to alter the pulse rate.

\section{METHODS AND MATERIALS}

During acute studies, arterial pressures were recorded through an indwelling brachial or femoral arterial needle by means of a Statham P 23 A pressure transducer and a Sanborn direct writing oscillograph. Cardiac output was measured by direct Fick principle with the technique of right heart catheterization. Blood gases were analyzed by the method of Van Slyke and Neill (7). Expired gases were analyzed with a Beckman Oxygen 
Analyzer, Model E-2, and a Cambridge Carbon Dioxide Analyzer. Effective renal plasma flow was measured by means of the renal clearance of para-aminohippurate (8). Glomerular filtration rate was measured by means of the clearance of inulin (9). Urine was collected by means of an indwelling six-hole rubber urethral catheter. At the beginning and end of each collection period, the bladder was emptied with $40 \mathrm{ml}$. of air unless the urine volume was greater than $10 \mathrm{ml}$. per minute. During the studies in which antidiuretic hormone was administered, $21 / 2$ to 5 per cent mannitol was infused in an effort to maintain urine volume. The duration of the urine collection periods varied from 15 to 60 minutes.

Total peripheral vascular resistance was calculated according to the formula :

Peripheral resistance (dynes sec. $\left.\mathrm{cm} .^{-6}\right)=$

1332 (Mean femoral arterial pressure -

Mean right atrial pressure)

Cardiac output (ml./sec.)

The following posterior pituitary preparations were used: highly purified vasopressin and oxytocin, 2 whole posterior pituitary powder, Pitressin's and Pitressin' Tannate in Oil. The purified vasopressin had a concentration of $\mathbf{8 5}$ pressor units per milliliter and contained no oxytocin by amino acid analysis. The purified oxytocin had a concentration of 400 units per milliliter expressed as oxytocic units. It possessed approximately 1/1,000 of the antidiuretic activity of the purified vasopressin when studied in four normal persons in the hydrated state.

\section{RESULTS}

\section{Effect of posterior pituitary hormones}

Normal subjects. Six normal subjects, ages 18 to 21 , were given intravenous infusions of 3.4 to

2 We are indebted to Dr. Vincent du Vigneaud who supplied the highly purified vasopressin and oxytocin.
15.7 units of Pitressin in saline per hour for a two-hour period. During control studies, on another day, an equal volume of saline was infused at the same rate ( 3 to 4 milliliters per minute). As observed by previous investigators $(1,2)$, infusion of Pitressin had no significant effect on the arterial pressures of these subjects. Single intravenous injections of 500 to $1,000 \mathrm{mU}$ of Pitressin in 8 normal subjects resulted in a transient elevation of arterial pressure averaging $15 \mathrm{~mm}$. $\mathrm{Hg}$ systolic and $18 \mathrm{~mm}$. $\mathrm{Hg}$ diastolic, generally lasting 3 to 5 minutes.

Patients with orthostatic hypotension. Administration of Pitressin and highly purified vasopressin to the patients in the recumbent position resulted in an immediate rise in systolic and diastolic arterial pressure in all three patients. The immediate response to a single injection of 100 $\mathrm{mU}$ of vasopressin intravenously in patient $\mathrm{H}$. C. is illustrated in Figure 1. The elevation of the arterial pressure was related to the dose injected. Figure 2 shows the effect of graded intravenous infusions of 1 to $20 \mathrm{mU}$ per minute of highly purified vasopressin on the arterial pressure of patient W. A.

Patients H. C. and W. A. had a significant rise of brachial arterial pressure when given one milliunit per minute of vasopressin by continuous infusion, and following a single intravenous injection of 10 milliunits. Patient B. B. had no elevation of arterial pressure with one milliunit per minute for 15 minutes, but a rise of $100 \mathrm{~mm}$. $\mathrm{Hg}$ systolic when infused with 10 milliunits per minute for $10 \mathrm{~min}$ -

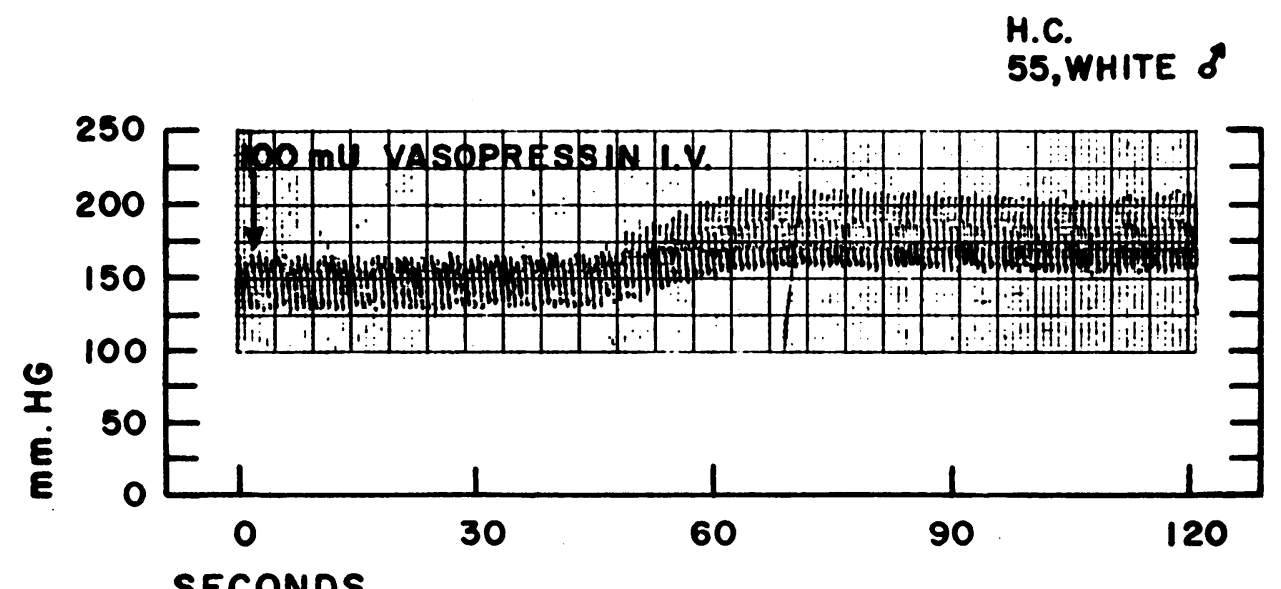

Fig. 1. Brachial Arterial Pressure Following the Single Intravenous Injection of 100 mU Vasopressin in Patient H. C. 


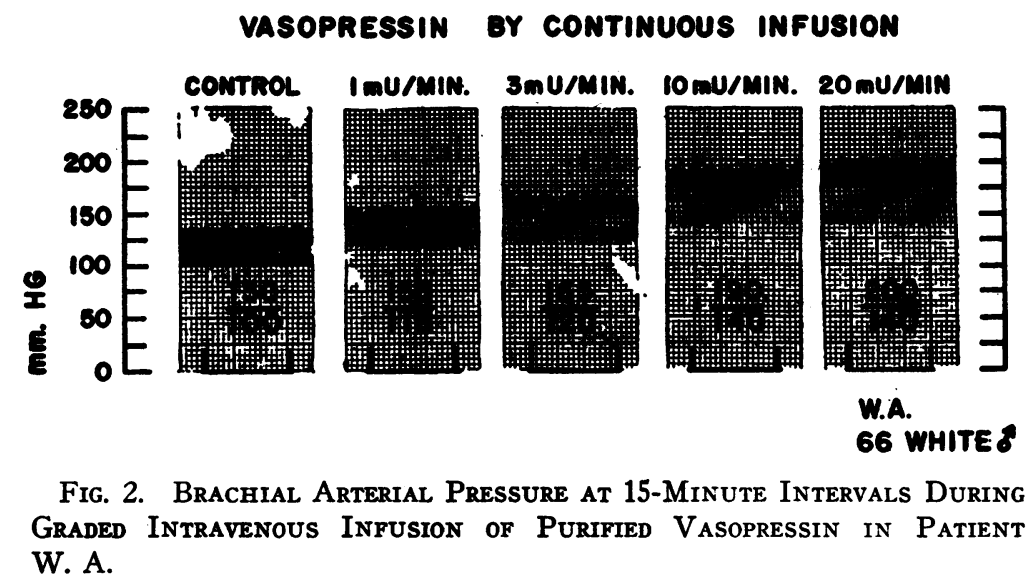

utes. In each patient, arterial pressures in the hypertensive range were observed following the intravenous injection of $1,000 \mathrm{mU}$ of purified vasopressin. The patients had a rise in arterial pressure to sustained hypertensive levels exceeding $170 / 100 \mathrm{~mm} . \mathrm{Hg}$ when the following preparations were administered during recumbency : whole posterior pituitary powder by nasal inhalation, Pitres$\sin { }^{(2)}$ by subcutaneous injection, and Pitressin ${ }^{(}$ Tannate in Oil intramuscularly. Table I shows the brachial arterial pressures in each patient following single intravenous injections of vasopressin.

The effects of oxytocin, the second polypeptide of the posterior pituitary, were also studied. In eight normal subjects intravenous infusion of 10

TABLE I

Effect of single intravenous injections of vasopressin and oxytocin on the brachial arterial pressure of patients with primary autonomic insufficiency

Vasopressin

Average arterial pressure 0-20 minutes after single intravenous injection of vasopressin

\begin{tabular}{lrlll}
\hline Patient & Control & \multicolumn{1}{c}{$10 m U$} & $100 m U$ & $1000 m U$ \\
\hline H. C. & $96 / 70$ & $128 / 76$ & $158 / 96$ & $200 / 130$ \\
B. B. & $120 / 98$ & $134 / 110$ & $152 / 130$ & $164 / 136$ \\
W. A. & $94 / 58$ & $104 / 65$ & $126 / 80$ & $170 / 110$ \\
\hline
\end{tabular}

Oxytocin

Lowest arterial pressure after single intravenous injection of oxytocin

\begin{tabular}{lll}
\hline Patient & Control & $1000 \mathrm{mU}$ \\
\hline H. C. & $138 / 110$ & $65 / 45$ \\
B. B. & $100 / 76$ & $48 / 34$ \\
W. A. & $102 / 70$ & $50 / 38$ \\
\hline
\end{tabular}

to 20 units of purified oxytocin per hour for two hours had no significant effect on the arterial pressure. Highly purified oxytocin had a marked but transient depressor effect followed by a period of hypertension when administered intravenously to all three patients in the recumbent position. The depressor effect of one unit of oxytocin on one of the patients is illustrated in Figure 3 . Table I shows the arterial pressure resulting from a single intravenous injection of one unit of oxytocin in each of the patients.

\section{Mechanism of the pressor effect of vasopressin}

Effect on cardiac output and total systemic vascular resistance. Having demonstrated a pressor effect of vasopressin, an attempt was made to determine if the effect was related to an increase in cardiac output, an increase in peripheral resistance, or both.

In two of the patients, H. C. and B. B., cardiac output and femoral arterial pressure were measured in the recumbent position before and following the administration of vasopressin. Table II summarizes the results of these studies. No significant change in the cardiac output occurred in association with a marked rise in femoral arterial pressure. Total peripheral vascular resistance increased from 1,670 to 2,515 dyne sec. $\mathrm{cm}^{-5}$ in patient $H$. C., and from 1,350 to 1,975 dynes sec. $\mathrm{cm}^{-5}$ in patient B. B.

Effect on glomerular filtration rate, effective renal plasma flow, and renal vascular resistance. In view of the hemodynamic effects of vasopressin in these patients, an effort was made to determine its possible renal vascular activity. Table III 
OXYTOCIN

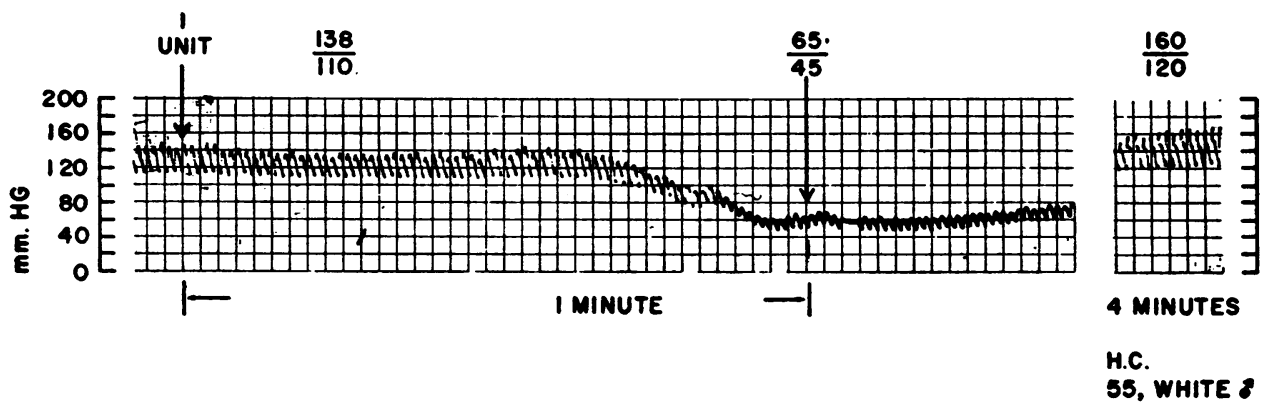

Fig. 3. Brachial Artery Pressure following the Single Intravenous Injection of One Unit of Oxytocin in Patient H. C.

shows the results of a study on patient B. B. It can be seen that there was a fall of the effective renal plasma flow in association with a rise of the systemic arterial pressure evidencing an increase in renal vascular resistance. The glomerular filtration rate was not changed, indicating an increase in filtration fraction. In other studies of patient B. B., and in patients H. C. and W. A., there were similar depressions of the effective renal plasma flow, with a rise in the filtration fraction in association with vasopressin administration. Thus, in each patient renal vascular resistance increased in association with the arterial pressure rise following vasopressin administration.

Effect on pulmonary arterial pressure. In two patients studied, a significant elevation of the pulmonary arterial pressure occurred subsequent to vasopressin administration. The results are shown in Table II.

Effect of ganglionic blockade on response to vasopressin. Four persons without evidence of orthostatic hypotension were given intravenous injections of the ganglionic blocking agent, tetraethylammonium chloride (TEA). In these persons, vasopressin had not previously had a significant pressor effect when injected intravenously. However, when vasopressin was administered subsequent to ganglionic blockade, a pressor response occurred in each subject. This rise in arterial pressure did not occur following control injections of TEA alone. The results of these studies are seen in Table IV.

\section{DISCUSSION}

The three patients studied had severe postural hypotension, hypohidrosis and impotence, a clinical syndrome distinct from the postural hypotension associated with general debility, diabetes mellitus, amyloidosis, Addison's disease and various neurological disorders. Involvement of the sympathetic nervous system of these patients is

TABLE II

Effect of vasopressin infusion on cardiac index, systemic and pulmonary arterial pressures and systemic resistance

\begin{tabular}{|c|c|c|c|c|c|c|c|c|}
\hline \multirow[b]{2}{*}{ Pt. } & \multirow[b]{2}{*}{ State } & \multirow{2}{*}{ 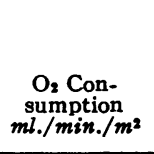 } & \multirow{2}{*}{$\begin{array}{c}\text { Cardiac } \\
\text { index } \\
L . / m i n . / m^{2}\end{array}$} & \multicolumn{2}{|c|}{$\begin{array}{c}\text { Femoral } \\
\text { art. press. } \\
\mathbf{m m} . \mathbf{H g}\end{array}$} & \multirow{2}{*}{$\begin{array}{c}\text { Systemic } \\
\text { resistance } \\
\text { dynes sec. } \mathrm{cm} .^{-\mathrm{s}}\end{array}$} & \multicolumn{2}{|c|}{$\begin{array}{l}\text { Pulmonary } \\
\text { art. press. } \\
m \boldsymbol{m} . \mathrm{Hg}\end{array}$} \\
\hline & & & & $\begin{array}{l}\text { Syst./ } \\
\text { Diast. }\end{array}$ & Mean & & $\begin{array}{l}\text { Syst./ } \\
\text { Diast. }\end{array}$ & Mean \\
\hline \multirow[t]{2}{*}{ H. C. } & \multirow{2}{*}{$\begin{array}{l}\text { Control } 1 \\
\text { Control } 2 \\
\text { Vasopressin* } \\
\text { infusion }\end{array}$} & $\begin{array}{l}121 \\
115\end{array}$ & $\begin{array}{l}2.05 \\
2.14\end{array}$ & $\begin{array}{r}96 / 68 \\
102 / 70\end{array}$ & $\begin{array}{l}78 \\
81\end{array}$ & $\begin{array}{l}1,665 \\
1,670\end{array}$ & $\begin{array}{l}17 / 10 \\
16 / 9\end{array}$ & $\begin{array}{l}12 \\
12\end{array}$ \\
\hline & & 128 & 1.95 & $134 / 90$ & 110 & 2,515 & $22 / 15$ & 18 \\
\hline \multirow{2}{*}{ B. B. } & \multirow{2}{*}{$\begin{array}{l}\text { Control } \\
\text { Vasopressint } \\
\text { infusion }\end{array}$} & 107 & 2.85 & $103 / 70$ & 84 & 1,350 & $21 / 8$ & 12 \\
\hline & & 124 & 2.69 & $145 / 89$ & 110 & 1,975 & $28 / 15$ & 19 \\
\hline
\end{tabular}

* $1 \mathrm{mU} /$ minute.

$+3 \mathrm{mU} /$ minute. 
TABLE IH

Effect of vasopressin on renal function and arterial pressure*

Patient B. B.

Time

9:05 Infusion of $21 \%$ mannitol containing $20 \mathrm{mgm} . /$ minute inulin and $10 \mathrm{mgm} . / \mathrm{minute} \mathrm{PAH}$ at a rate of $8.6 \mathrm{ml} . /$ minute begun.

\begin{tabular}{|c|c|c|c|c|c|c|c|}
\hline Time & $\begin{array}{c}\text { Urine } \\
\text { volume } \\
\text { ml./min. }\end{array}$ & $\begin{array}{l}\text { Blood } \\
\text { pressure } \\
\mathbf{m m} . \mathbf{H g}\end{array}$ & $\begin{array}{c}\text { Length of } \\
\text { period } \\
\text { min. }\end{array}$ & $\underset{m b . / \min .}{\mathrm{C}_{\mathbf{P A B}}}$ & $\underset{m b . / m i n}{\mathrm{C}_{1 \mathrm{~N}}}$ & F.F. & $\begin{array}{c}\text { Renal } \\
\text { vascular } \\
\text { resistance } \\
\text { dyne sec. } \mathrm{cm} .^{-5} \\
\times 10^{-3}\end{array}$ \\
\hline $\begin{array}{l}10: 30 \\
10: 45 \\
11: 00 \\
11: 00 \\
11: 15 \\
11: 45 \\
12: 05 \\
12: 25\end{array}$ & $\begin{array}{l}5.4 \\
7.5 \\
7.3 \\
\text { Subcu } \\
4.7 \\
2.3 \\
3.2 \\
3.9\end{array}$ & $\begin{array}{c}79 / 56 \\
106 / 74 \\
106 / 70 \\
\text { us injectio } \\
160 / 96 \\
170 / 100 \\
164 / 94 \\
164 / 92\end{array}$ & $\begin{array}{c}15 \\
15 \\
15 \\
5 \text { units of } \\
15 \\
30 \\
20 \\
20\end{array}$ & $\begin{array}{c}323 \\
346 \\
323 \\
\text { pressin } \\
294 \dagger \\
204 \\
222 \\
197\end{array}$ & $\begin{array}{l}60 \\
75 \\
78 \\
\\
57 \dagger \\
68 \\
75 \\
69\end{array}$ & $\begin{array}{l}0.186 \\
0.216 \\
0.242\end{array}$ & $\begin{array}{l}31.5 \\
27.5 \\
30.7\end{array}$ \\
\hline
\end{tabular}

* $\mathrm{C}_{\mathrm{IN}}=$ Inulin clearance.

$\mathrm{C}_{\mathrm{PAH}}=$ Para-aminohippurate clearance.

F.F. = Filtration fraction.

† These data have been discarded. Volume changes occurred that made accurate determinations of inulin and PAH impossible because of delay time and dead space.

indicated by the diminished sweating, postural hypotension and absence of hypertensive "overshoot" following Valsalva maneuver (10). However, all features of the syndrome cannot be explained by a lesion of the sympathetic nervous system only. Abnormalities of the parasympathetic nervous system in all three patients were suggested by : 1) the failure of atropine to alter the pulse rate;2) the absence of bradycardia during administration of norepinephrine and neostigmine; 3 ) the lack of effect on the pulse rate and arterial pressure of carotid sinus massage; 4) the inability to have erections ; 5) the failure of hypoglycemia to produce an increase in gastric acidity. ${ }^{3}$ Thus, this

3 The hypoglycemia study was conducted in only two patients. disease, which may be called Primary Autonomic Insufficiency, appears to be diffuse, involving portions of the parasympathetic as well as the sympathetic nervous system. The syndrome in our three patients is most closely simulated in normal man by ganglionic blocking agents.

In these patients with diffuse autonomic nervous system disease, vasopressin in very small doses resulted in a pressor response and significant hemodynamic changes. Since one milliunit per minute of vasopressin approaches the physiologic range of antidiuretic hormone secretion (11), it is possible that endogenous antidiuretic hormone may have a significant hemodynamic effect. Attempts to evaluate the hemodynamic effects of endogenous antidiuretic hormone have thus far

TABLE IV

Effect of vasopressin on arterial pressure during ganglionic blockade*

\begin{tabular}{|c|c|c|c|c|c|c|}
\hline Subject & $\begin{array}{l}\text { Control } \\
\text { B.P. }\end{array}$ & $\begin{array}{c}\text { Average B.P. } \\
\text { 0.5-20 min. } \\
\text { after } \\
300-400 \text { mgm. } \\
\text { TEA I.V. }\end{array}$ & $\begin{array}{c}\text { Control } \\
\text { B.P. }\end{array}$ & $\begin{array}{c}\text { Average B.P. } \\
5-20 \mathrm{~min} . \\
\text { after } \\
500 \mathrm{mU} \\
\text { Pitressin @ I.V. }\end{array}$ & $\begin{array}{c}\text { Control } \\
\text { B.P. }\end{array}$ & $\begin{array}{c}\text { Average B.P } \\
5-20 \mathrm{~min} . \\
\text { after } \\
500 \mathrm{mU} \\
\text { Pitressin (8) } \\
\text { after TEA }\end{array}$ \\
\hline $\begin{array}{l}\text { Y.S. } \\
\text { G.E. } \\
\text { M. G. } \\
\text { M. U. }\end{array}$ & $\begin{array}{l}120 / 80 \\
106 / 58 \\
132 / 80 \\
180 / 90\end{array}$ & $\begin{array}{l}118 / 79 \\
101 / 61 \\
128 / 80 \\
183 / 95\end{array}$ & $\begin{array}{l}130 / 85 \\
120 / 64 \\
132 / 82 \\
170 / 80\end{array}$ & $\begin{array}{l}125 / 94 \\
131 / 82 \\
140 / 87 \\
170 / 82\end{array}$ & $\begin{array}{l}122 / 80 \\
110 / 64 \\
132 / 82 \\
188 / 92\end{array}$ & $\begin{array}{l}158 / 108 \\
138 / 102 \\
156 / 106 \\
228 / 110\end{array}$ \\
\hline
\end{tabular}

* The administration of Pitressin (2) alone, tetraethylammonium chloride (TEA) alone, and Pitressin (- administered 5 minutes after TEA was observed on separate occasions. Arterial pressures were measured by sphygmomanometry at one-minute intervals. Control periods were at least 20 minutes. 
been unsuccessful in these patients. Administration of nicotine acid tartrate (12) failed to elicit any antidiuretic response. Changes in plasma osmolality (as in dehydration) resulted in extracellular fluid volume changes which in themselves were associated with pronounced effects on systemic arterial pressure in these patients.

The pressor activity of vasopressin in these patients is possibly related to supersensitivity of the vascular smooth muscle $(12,13)$ and/or the diminution of normal vasoregulatory reflexes which may counteract the vasoconstricting effect of vasopressin in normal persons. The importance of the latter factor is suggested by the finding that these patients have an exaggerated arterial pressure response to various vasoactive substances, such as norepinephrine and oxytocin. The fact that plasma volume changes, such as those associated with rapid withdrawal of blood and intravenous infusions of albumin and saline, have marked effects on the arterial pressure also supports the concept that vasoregulatory mechanisms are markedly deficient.

A number of workers have shown that the pressor action of epinephrine, norepinephrine, angiotonin and renin is greatly increased after ganglionic transmission is blocked by tetraethylammonium chloride $(14,15,16)$. The present observations of the pressor action of vasopressin in the absence of normal function of the autonomic nervous system suggest that autonomic nervous system activity may normally condition the hemodynamic response to the antidiuretic principle of the posterior pituitary as well as to these other substances. The present studies revealed that vasopressin has a pressor effect when given to normal man during chemical ganglionic blockade.

The finding that vasopressin has a marked pressor effect in patients with this type of postural hypotension led to an evaluation of the therapeutic value of vasopressin in these patients. Pitres$\sin$ Tannate in Oil has been repeatedly administered to one patient. Following his morning injection he obtained complete relief of his postural symptoms throughout the entire day.

The other two patients have obtained less but definite subjective and objective relief of hypotensive symptoms following intramuscular Pitressin ${ }^{\circledR}$ Tannate in Oil and whole posterior pituitary powder by nasal inhalation. In all patients dur- ing vasopressin therapy, a postural fall in arterial pressure was still noted, but, in contrast to the untreated state, the pressure did not fall to levels associated with symptoms. No effect on impotence or anhidrosis was observed.

Two potential complications of vasopressin in therapy must be considered. In patients with coronary artery disease, vasopressin in large doses may result in myocardial ischemia. In our patients no electrocardiographic changes occurred, nor was there any clinical evidence of angina pectoris. Nevertheless, this potential hazard of the use of vasopressin must be emphasized (17). A second possible complication is water intoxication which can be avoided by restricting fluid intake.

\section{SUMMARY}

1. Three patients with the syndrome of idiopathic postural hypotension, hypohidrosis and impotence were studied.

2. Although antidiuretic substances from the posterior pituitary had no significant effect on the arterial pressure of normal man, administration of various posterior pituitary hormones to these patients had a pronounced effect on systolic and diastolic arterial pressures.

Hypertension in the recumbent position was produced in all patients by whole posterior pituitary powder administered by nasal insufflation, intra-muscular injection of Pitressin Tannate in Oil, and subcutaneous and intravenous administration of highly purified vasopressin. Administration of purified oxytocin resulted in marked but transient hypotension.

3 . In the two patients studied, the pressor response was produced by an increase in peripheral vascular resistance without significant change in the cardiac output. Vasopressin resulted in a significant increase in pulmonary arterial pressure and in renal vascular resistance.

4. In normal subjects the administration of vasopressin subsequent to ganglionic blockade with tetraethylammonium chloride resulted in a significant elevation of arterial pressure.

5. Vasopressin has been of value in the management of orthostatic hypotension of this type.

\section{ACKNOWLEDGMENT}

We are indebted to Dr. Roger K. McDonald for his cooperation in this study. 


\section{Addendum}

Since preparation of this manuscript, the observations of the marked pressor effect of vasopressin have been confirmed in two additional patients with the syndrome of primary autonomic insufficiency.

\section{REFERENCES}

1. Grollman, A., and Geiling, E. M. K., Cardiovascular and metabolic reactions of man to intramuscular injection of posterior pituitary liquid (Pituitrin), Pitressin and Pitocin. J. Pharmacol. \& Exper. Therap., 1932, 46, 447.

2. Graybiel, A., and Glendy, R. E., Circulatory effects following the intravenous administration of Pitressin in normal persons and in patients with hypertension and angina pectoris. Am. Heart J., 1941, 21, 481.

3. Rowe, L. W., Studies on oxytocin and vasopressin: pressor action. Endocrinology, 1929, 13, 205.

4. Hogben, L. T., and Schlapp, W., Studies on the pituitary. III. The vasomotor activity of pituitary extracts throughout the vertebrate series. Quart. J. Exper. Physiol., 1924, 14, 229.

5. Bradbury, S., and Eggleston, C., Postural hypotension, a report of three cases. Am. Heart J., 1925, 1, 73.

6. Sarnoff, S. J., Hardenbergh, E., and Whittenberger, J. L., Mechanism of the arterial pressure response to the Valsalva test: The basis for its use as an indicator of the intactness of the sympathetic outflow. Am. J. Physiol., 1948, 154, 316.

7. Van Slyke, D. D., and Neill, J. M., The determination of gases in blood and other solutions by vacuum extraction and manometric measurement. J. Biol. Chem., 1924, 61, 523.

8. Smith, H. W., Finkelstein, N., Aliminosa, L., Crawford, B., and Graber, M., The renal clearances of substituted hippuric acid derivatives and other aromatic acids in dog and man. J. Clin. Invest., 1945, 24, 388.

9. Walser, M., Davidson, D. G., and Orloff, J., The renal clearance of alkali-stable inulin. J. Clin. Invest., $1955,34,1520$.

10. Stead, E. A., and Ebert, R. V., Postural hypotension, a disease of the sympathetic nervous system. Arch. Int. Med., 1941, 67, 546.

11. Lauson, H. D., The problem of estimating the rate of secretion of antidiuretic hormone in man. Am. J. Med., 1951, 11, 135.

12. Lewis, A. A. G., and Chalmers, T. M., A nicotine test for the investigation of diabetes insipidus. Clin. Sc., 1951, 10, 137.

13. Krogh, A., The Anatomy and Physiology of Capillaries. New Haven, Yale University Press, 1929, p. 182

14. Page, I. H., and Taylor, R. D., Mechanism of renin tachyphylaxis. Restoration of responsiveness by tetraethyl ammonium ion. Science, 1947, 105, 622.

15. Bartorelli, C., Carpi, A., and Cavalca, L., Potentiation of the pressor action of nor-adrenaline by hexamethonium, tetraethylammonium, and methantheline. Brit. J. Pharmacol., 1954, 9, 476.

16. Wilber, J. A., and Brust, A. A., Pressor potentiation of nor-epinephrine by tetraethylammonium chloride and atropine. J. Clin. Invest., 1956, 35, 744 (Abstract).

17. Slotnik, I. L., and Teigland, J. D., Cardiac accidents following vasopressin injection (Pitressin). J. A. M. A., 1951, 146, 1126. 